\title{
Maternal Undernutrition and Type 2 Diabetes in Australian Aboriginal and Torres Strait Islander People: History and Future Direction
}

\author{
Dean V. Sculley ${ }^{1 *}$ and Mark Lucock ${ }^{2}$ \\ ${ }^{1}$ School of Biomedical Sciences and Pharmacy, University of Newcastle, NSW 2258, Australia; \\ ${ }^{2}$ School of Environmental \& Life Sciences, University of Newcastle, NSW 2258, Australia
}

\begin{abstract}
Type 2 diabetes is one of the most common chronic disease conditions, accounting for the majority of the 415 million diabetes cases worldwide. Australia currently has 1.7 million diabetics, with a prevalence among Australian Aboriginal and Torres Strait Islander populations 4-5 times that seen in non-indigenous Australians. The financial burden amounts to AU\$14.6 billion per year. Known risk factors for type 2 diabetes are being overweight or obese, hypertension, a sedentary lifestyle, low concentration of high density lipoprotein, depression and family history. Nutrient restriction during pregnancy can program alterations to organs and systems in the developing fetus due to intrauterine growth restriction. This plasticity, known as the 'thrifty phenotype', has been implicated in a wide range of adult disease conditions, including type 2 diabetes. Developmental programming via epigenetic mechanisms has resulted in a reduction of pancreatic beta cell mass, disruption of glucose transport proteins and signaling, and earlier onset of glucose intolerance of offspring, and is transgenerational in nature. Indigenous populations around the world appear to be at greater risk of programming effects, thought to be a consequence of rapid dietary and lifestyle changes. Interventions aimed at ensuring adequate maternal nutrition may reduce the extent of the deleterious epigenetic modifications and reduce the prevalence of type 2 diabetes in Australian Aboriginal and Torres Strait Islander populations.
\end{abstract}

\section{Introduction}

There is little doubt that type 2 diabetes is one of the major causes of death worldwide, with only heart disease, stroke and respiratory conditions having a higher mortality rate. ${ }^{1}$ Diabetes is also the fastest growing global chronic disease. ${ }^{2}$ According to the International Diabetes Federation, 415 million people worldwide have diabetes, most of whom have type 2 diabetes. This number is expected to rise to 642 million by $2040 .^{3}$ Indeed, a recent article by Paul Zimmet suggests diabetes may be the largest epidemic in human history and presents the greatest challenge to health. ${ }^{4}$ There are a number of risk factors associated with type 2 diabetes,

Keywords: Maternal diet; Low protein; Developmental programming; Type 2 diabetes.

Abbreviations: DNMT, DNA methyltransferase; IUGR, intrauterine growth restriction.

Received: August 01, 2017; Revised: November 9, 2017; Accepted: November 14, 2017 *Correspondence to: Dean V Sculley, School of Biomedical Sciences and Pharmacy, University of Newcastle, Brush Rd, Ourimbah, NSW 2258, Australia. Tel: (0)2 4349 4596, E-mail: dean.sculley@newcastle.edu.au

How to cite this article: Sculley DV, Lucock M. Maternal Undernutrition and Type 2 Diabetes in Australian Aboriginal and Torres Strait Islander People: History and Future Direction. Exploratory Research and Hypothesis in Medicine 2017;2(4):117121. doi: 10.14218/ERHM.2017.00028. including being overweight or obese, hypertension, family history, low high-density lipoprotein, sedentary lifestyle and depression. ${ }^{5}$

Australia has a population of around 24.4 million as of the end of $2016 .^{6}$ The number of Australians with diabetes totals around 1.7 million, or $7 \%$ of the population. This figure contains 1.2 million diagnosed, with an estimated 500,000 undiagnosed, with type 2 diabetes making up $85-90 \%$ of cases. Combined, the annual cost of treating and managing diabetes in Australia is AU\$14.6 billion. ${ }^{7}$ What is more disturbing is the disparity between Australian Aboriginal and Torres Strait Islanders and non-Aboriginal Australians, with the former having a diabetes prevalence around 4-5 times that of non-Aboriginal Australians. ${ }^{8}$ This figure, coupled with the reduced access to adequate health care facilities, represents a major health issue in Australia.

This imbalance in the incidence and prevalence of type 2 diabetes is not just observed in Australian Aboriginal and Torres Strait Islander populations. Significantly higher numbers are seen in African American, Alaska Native, American Indian, Asian American, Hispanic/Latino, Native Hawaiian and Pacific Islander people. ${ }^{5}$ This is a fairly recent phenomenon, with some of the highest prevalence of diabetes discovered amongst Australian Aborigines, ${ }^{9}$ Pima Indians and Pacific Islanders. ${ }^{10,11}$ More recently, diabetes has been reported to affect around $8.7 \%$ of Asian Indians, ${ }^{12}$ and increasing from $2.6 \%$ in 2002 to $9.7 \%$ in 2012 in the rapidly-mod- 
ernizing economy of China. ${ }^{12,13}$ Current figures from the World Health Organization show that $10 \%$ of the population, or 110 million people, suffer with diabetes in China. ${ }^{14}$ These data suggest there must be specific reasons, possibly genetic or epigenetic, why certain populations endure higher rates of diabetes.

\section{Change of lifestyle}

To better understand why these indigenous populations, including Australian Aboriginal and Torres Strait Islander peoples, are at greater risk of developing diabetes we need to look at what environmental and lifestyle changes have accompanied the increased incidence and prevalence, together with an examination of the specific genetic risk factors. It had been generally assumed that Australia was populated somewhere between 40,000-100,000 years ago and that it remained isolated, barring occasional visits from Asian fishermen and European seafarers, until the late 18th century. ${ }^{15-17}$ However, more recent discoveries in excavations in northern Australia now indicate human occupation at around 65,000 years ago. ${ }^{18}$

Whilst data pertaining to the health and condition of Australian Aborigines prior to European settlement is difficult to establish, a study of isolated populations living the traditional hunter-gatherer lifestyle around 50 years ago reported an average height of 167.1 $\mathrm{cm}$ and average weight below $56 \mathrm{~kg} .{ }^{19}$ Foods eaten were dictated by the locality and seasonal availability and included kangaroo, wallaby, possum, bandicoot, snakes, turtles, goanna, bush turkey, fish and other seafood, in addition to a variety of fruits, nuts and seeds. ${ }^{17}$ By the 1960 s, the way of life for a large number of remote Australian Aborigines had changed dramatically. Many were living in camps and missions, with the available food containing large amounts of refined flour, milk powder, fat and sugar, whilst being deficient in key micronutrients, including vitamin $\mathrm{A}$ and $\mathrm{C}$, folate and calcium. ${ }^{17,20}$

Milk powder is of specific interest, as studies have found lactose intolerance figures of between $84-95 \%$ in children from the Northern Territory, with these children being in the lowest percentile for height and weight. ${ }^{21}$ In a more recent study, the poor and restrictive diet was found to result in low birth weight, followed by rapid 'catch-up growth' to around 6 months of age with a subsequent reduction in growth to 5 years, after which records are difficult to find. ${ }^{22}$ This is of great significance for future disease susceptibility, including type 2 diabetes.

The rapid loss of the active hunter-gatherer existence, coupled with an extensive change of diet and societal structure, has had both a severe physiological and psychological impact. Australian Aborigine and Torres Strait Islander peoples aged 15 years or over were found to be more overweight or obese than non-indigenous people (1.2 times), with $29 \%$ being classified as overweight and $37 \%$ obese. They are also 1.2 times more likely to have high blood pressure ( $\geq 149 / 90 \mathrm{mmHg})$ than non-indigenous people, with $20 \%$ of Australian Aborigines and Torres Strait Islanders being hypertensive.

Blood lipid analysis found that $25 \%$ of Australian Aborigines and Torres Strait Islanders had high total cholesterol $(\geq 5.5$ $\mathrm{mmol} / \mathrm{L}), 25 \%$ had high low-density lipoprotein cholesterol $(\geq 3.5$ $\mathrm{mmol} / \mathrm{L}), 40 \%$ had low levels of high-density lipoprotein cholesterol (males $<1.0 \mathrm{mmol} / \mathrm{L}$, females $<1.3 \mathrm{mmol} / \mathrm{L}$ ) and $25 \%$ had high blood triglycerides $(\geq 2.0 \mathrm{mmol} / \mathrm{L})$. The same study found $42 \%$ of Australian Aborigines and Torres Strait Islanders over the age of 15 years smoked regularly, 2.6 times more than non-indigenous people. From a dietary perspective, an inadequate intake of fruit and vegetables was reported, with $93 \%$ of Australian Aboriginals and Torres Strait Islanders over the age of 2 years failing to reach the minimum fruit and vegetable intake; a figure rising to $97 \%$ in over 15 year-olds. ${ }^{23,24}$

\section{Developmental programming}

This array of detrimental physiological markers represents key risk factors for the development of insulin resistance and type 2 diabetes and goes some way towards explaining the higher prevalence of these disorders in Australian Aboriginal and Torres Strait Islander peoples. Certainly, when lifestyle and nutritional intake were re-established to more traditional conditions (i.e. bush living and eating foods including crocodile, kangaroo and native plants), individuals displayed a reduction in adiposity and beneficial effects with respect to glucose tolerance, insulin sensitivity, blood lipid profile and blood pressure. ${ }^{25}$ However, we may not be looking at the complete picture.

While there is little doubt that improving diet and exercise reduces the risk of developing type 2 diabetes, the effects of inadequate nutritional intake and disease during pregnancy may predispose offspring to a greater risk of diseases, including type 2 diabetes, in later life. Research pioneered by David Barker in the 1990s initially found the link between low birthweight and an increased prevalence of coronary heart disease in populations in northern England in the early 20th century. ${ }^{26}$ This was followed up by more detailed analysis of records from Hertfordshire, UK (the Hertfordshire Cohort Study), where low birthweight was associated with an increased risk of death by circulatory diseases. ${ }^{26,27}$ Further study revealed insulin resistance and type 2 diabetes to be strongly correlated to low birthweight. ${ }^{28}$

Periods of famine have provided additional insight into the effects of nutrient restriction and development of the fetus. The Dutch Hunger Winter, or Dutch Famine, occurred towards the end of 1944 and was the result of a Nazi food blockade to western regions of the Netherlands. The fate of offspring born to mothers who suffered severe nutrient restriction during this period has been extensively studied. ${ }^{29}$ Offspring exposed to nutrient restriction in utero showed increased blood glucose concentrations, ${ }^{30}$ hypertension and coronary heart disease. ${ }^{31,32}$ A similar pattern emerged in China after the 1958-62 famine. Prior to 1980, diabetes was almost non-existent in China; however, over 120 million Chinese now suffer from diabetes. ${ }^{33}$ A parallel study on the same population found an increased prevalence of hypertension. ${ }^{33,34}$

This phenomenon became known as the 'thrifty phenotype hypothesis', and its basic premise is that in a suboptimal in utero environment, the fetus' metabolic development changes in order to maximize survival in post-natal nutritional insufficiency. ${ }^{35}$ However, if the nutritional availability is not limited and offspring have access to a normal or obesogenic diet, the physiological adaptations during gestation can predispose it to developing a variety of metabolic disorders, such as diabetes and hypertension. ${ }^{36,37}$ This branch of research now falls under the title of Developmental Origins of Health and Disease, as early life factors can also impact later disease status. ${ }^{38}$

Further research has identified other factors that can influence fetal and early-life development, including smoking, maternal stress, gestational diabetes and maternal obesity. ${ }^{39}$ These disruptions to fetal development and future disease risk do not appear to be confined to the first generation. Programming effects have also been found in the second generation, indicating a trans-generational process and signaling longer term plastic adaptations. ${ }^{40}$ 


\section{Epigenetic effects of developmental programming}

So, just how does a disruption to maternal nutrition cause such a deleterious effect on offspring and increase their risk of developing type 2 diabetes? This article will focus on one of the main nutritional factors believed to confer these effects on a developing fetus - maternal low-protein diet. This is arguably one of the most relevant scenarios due to the change in diet of Australian Aborigines and Torres Strait Islanders from a high-protein, high-fiber, low saturated fat diet to one favoring large quantities of highly-refined carbohydrates. ${ }^{41}$

It is generally accepted that the key mechanism driving developmental programming of fetal tissues and organs is epigenetic remodeling. Epigenetics encompass heritable factors that alter gene expression rather than the genetic code and includes DNA methylation, post-translational histone modification and non-coding RNAs, such as microRNAs. ${ }^{42}$ DNA methylation occurs at cytosine bases (CpG sites), where they are converted via DNA methyltransferase (DNMT) enzymes to 5-methylcytosine. DNA methylation serves to silence genes by inhibition of gene promoter activity and plays a vital role in embryonic development, chromosomal stability and X-chromosome inactivation. ${ }^{43}$ This was demonstrated in a study where DNMT-knockout mice died early in development. ${ }^{43,44}$ Post-translational histone modification also affects gene expression early in mammalian development via histone acetylation and deacetylation. Acetylation by histone acetyltransferase enzymes adds an acetyl group and reduces the bond between DNA and histones, thereby generally increasing transcription rates. Histone deacetylase enzymes produce a more condensed form of chromatin and reduce transcription rates. ${ }^{45}$ MicroRNA is a class of non-coding RNA typically between 20-25 nucleotides long, which have the capacity to reduce gene expression at the post-transcriptional level and also to inhibit gene expression of enzymes, including DNMT and histone deacetylase. ${ }^{46}$

\section{Programming effects on the pancreas and insulin resistance}

If the Developmental Origins of Health and Disease hypothesis relates to the development of type 2 diabetes, we should be able to observe epigenetic effects in two key areas-pancreatic islet $\beta$ cells, and insulin sensitivity in key organs and tissues such as the liver, skeletal muscle and adipose tissue. Fetal undernutrition, particularly that induced by a maternal low-protein diet, has been demonstrated to cause intrauterine growth restriction (IUGR), low birthweight and an increased adult prevalence of diseases including type 2 diabetes. ${ }^{28}$

More specifically, IUGR in rats via a maternal low-protein diet resulted in a reduction in pancreatic weight and mean islet $\beta$ cell area, thought to be due to a combination of reduced proliferative capacity and vascularity in the pancreas. After being fed a normal diet post-weaning, these same animals maintained a reduced islet $\beta$ cell mass in addition to a lower insulin content. ${ }^{47}$ Another study found similar results, with caloric restriction and low-protein models both producing a $20-40 \%$ reduction in islet $\beta$ cell mass at birth. ${ }^{48}$ This results in glucose intolerance at around 4 months of age and insulin resistance and type 2 diabetes by 17 months. ${ }^{49,50}$

These results are mirrored in human studies, where offspring exposed to IUGR demonstrate an increase in glucose intolerance in adulthood. ${ }^{51}$ Interestingly, the timing of maternal undernutrition is crucial, with both rat and human studies indicating a more deleterious effect if induced later in pregnancy. ${ }^{52,53}$ This is also in line with other studies investigating nephron number and renal func- tion using a similar IUGR model. ${ }^{54}$

Insulin functions to remove glucose from the blood when concentrations are high and promote glucose uptake into the liver, adipose tissue and skeletal muscle. Insulin resistance describes the situation where glucose uptake is inhibited. This results in prolonged hyperglycemia and/or hyperinsulinemia. ${ }^{55}$ As with pancreatic development, a poor maternal diet and IUGR results in an increased risk of developing insulin resistance in later life. ${ }^{56}$ In a study using both rats and humans, IUGR resulting in low birth weight lead to a significant reduction of glucose transporter 4 gene expression, thereby inhibiting blood glucose transportation into adipose tissue and skeletal muscle. ${ }^{57}$

Protein kinase $\mathrm{C}$-zeta is another protein that plays a major role in insulin-mediated glucose transport. Analysis of muscle taken from offspring subjected to IUGR and of low birth weight displayed a reduction in protein kinase $\mathrm{C}$-zeta concentration, indicating a decreased capacity to absorb glucose from the blood. This was coupled to a significantly higher blood insulin concentration after administration of an intravenous infusion of glucose..$^{58}$ These data suggest a strong influence of IUGR on key mechanisms responsible for glucose absorption from the blood to peripheral tissues and, in conjunction with the programming effects on pancreatic islet $\beta$ cells, implicate IUGR and low birth weight as major risk factors in the development of type 2 diabetes.

\section{Implications and perspective}

Whilst maternal undernutrition is only one determinant involved in programming and developmental plasticity, it remains a key modifiable risk factor. The shift from a high-protein to high carbohydrate diet looks to be a major driver of type 2 diabetes in offspring, brought about by inherited epigenetic modifications. These changes remain in future generations and could result in a habitual increase in disease risk. This effect seems to be more pronounced in Australian Aboriginals and Torres Strait Islanders, possibly due to the rapid change in diet and lifestyle.

With the colonization of Australia by Europeans and recent exposure to a potentially obesogenic diet, populations accustomed to a more restrictive diet may be more prone to its deleterious effects, as they have not been exposed to centuries of gradual dietary shift towards a high carbohydrate diet. A similar pattern has already been observed in other aboriginal populations around the world that may go some way to proving this point. ${ }^{59}$ Certainly, Australian Aboriginal populations with higher levels of European genetic admixture had a reduced prevalence of diabetes and glucose intolerance, which may indicate an additional genetic component to diabetes risk. ${ }^{60}$

Specific genetic variability between different populations is outside the remit of this article but further highlights the importance of the role of developmental programming in Australian Aboriginals and Torres Strait Islanders and goes some way towards explaining the higher prevalence rates of diabetes in these populations. If these indigenous populations with little to no European genetic admixture naturally present with a reduced ability to handle high carbohydrate load in their diet, the additional developmental programming effects on the pancreas and glucose transport proteins, as discussed earlier, would certainly exacerbate the situation.

Appropriate dietary intake during pregnancy, including an adequate protein component, may help to reduce the potentially damaging epigenetic changes and mediate the risk of type 2 diabetes in future generations. This is especially important considering the increase in both availability and affordability of an obesogenic 
diet to these offspring. A coordinated effort to provide suitable nutritional advice, together with the easy availability of essential nutrients, can potentially help to limit cases of type 2 diabetes in Australian Aboriginal and Torres Strait Islander peoples and reduce the burden of disease and the socio-economic disadvantage it entails. Ideally, this will be in conjunction with other potential risk factors, such as stress, gestational diabetes, obesity and smoking. Data collected regarding maternal nutritional status, fetal growth rates, birthweight and on-going growth rates and physiological markers of disease in offspring would provide valuable information and help to elucidate the role of developmental programming in type 2 diabetes in the Indigenous Australian and Torres Strait Islander populations.

\section{Conflict of interest}

The authors have no conflict of interests related to this publication.

\section{Author contributions}

Study conception (DVS, ML), review of the literature and writing of the article (DVS, ML).

\section{References}

[1] The top 10 causes of death. [Accessed June 28, 2017]. Available from: http://www.who.int/mediacentre/factsheets/fs310/en/.

[2] Diabetes globally. [Accessed June 29, 2017]. Available from: https:// www.diabetesaustralia.com.au/diabetes-globally.

[3] IDF diabetes atlas-Home. [Accessed June 28, 2017]. Available from: http://www.diabetesatlas.org/.

[4] Zimmet PZ. Diabetes and its drivers: the largest epidemic in human history? Clin Diabetes Endocrinol 2017;3(1). doi:10.1186/s40842016-0039-3.

[5] Risk factors for type 2 diabetes. [Accessed July 3, 2017]. Available from: https://www.niddk.nih.gov/health-information/diabetes/ overview/risk-factors-type-2-diabetes.

[6] Australian Demographic Statistics, Jun 2017. [Accessed June 29, 2017]. Available from: http://www.abs.gov.au/AUSSTATS/abs@.nsf/ $\mathrm{mf} / 3101.0$.

[7] Diabetes in Australia. [Accessed June 29, 2017]. Available from: https://www.diabetesaustralia.com.au/diabetes-in-australia.

[8] Aboriginal \& Torres Strait Islander people. [Accessed June 29, 2017]. Available from: https://www.diabetesaustralia.com.au/aboriginaland-torres-strait-islanders.

[9] Wise PH, Edwards FM, Thomas DW, Elliot RB, Hatcher L, Craig R. Hyperglycaemia in the urbanized Aboriginal. The Davenport survey. Med J Aust 1970;2(22):1001-1006.

[10] Bennett PH, Burch TA, Miller M. diabetes mellitus in American (Pima) Indians. Lancet 1971;2(7716):125-128. doi:10.1016/S01406736(71)92303-8.

[11] Zimmet P. Epidemiology of diabetes and its macrovascular manifestations in Pacific populations: the medical effects of social progress. Diabetes Care 1979;2(2):144-153. doi:10.2337/diacare.2.2.144.

[12] Pradeepa R, Mohan V. Prevalence of type 2 diabetes and its complications in India and economic costs to the nation. Eur J Clin Nutr 2017;71(7):816-824. doi:10.1038/ejcn.2017.40.

[13] Zhang N, Du SM, Ma GS. Current lifestyle factors that increase risk of T2DM in China. Eur J Clin Nutr 2017;71(7):832-838. doi:10.1038/ ejcn.2017.41.

[14] WPRORateofdiabetesinChina "explosive".[AccessedJuly3,2017].Available from: http://www.wpro.who.int/china/mediacentre/releases/ 2016/20160406/en/.

[15] Gillespie R. Dating the First Australians. Radiocarbon 2002;44(2):455-
472.

[16] Fullagar RLK, Price DM, Head LM. Early human occupation of northern Australia: archaeology and thermoluminescence dating of Jinmium rock-shelter, Northern Territory. Antiquity 1996;70:751-773. doi:10.1017/S0003598X00084040.

[17] Gracey M. Historical, cultural, political, and social influences on dietary patterns and nutrition in Australian Aboriginal children. Am J Clin Nutr 2000;72(5 Suppl):1361S-1367S.

[18] Clarkson C, Jacobs Z, Marwick B, Fullagar R, Wallis L, Smith M, et al. Human occupation of northern Australia by 65,000 years ago. Nature 2017;547(7663):306-310. doi:10.1038/nature22968.

[19] Elphinstone JJ. The health of Australian Aborigines with no previous association with Europeans. Med J Aust 1971;2(6):293-301.

[20] Lee AJ, O'Dea K, Mathews JD. Apparent dietary intake in remote aboriginal communities. Aust J Public Health 1994;18(2):190-197. doi:10.1111/j.1753-6405.1994.tb00224.x.

[21] Elliott RB, Maxwell GM, Vawser N. Lactose maldigestion in Australian Aboriginal children. Med J Aust 1967;1(2):46-49.

[22] Gracey M. New World syndrome in Western Australian aborigines. Clin Exp Pharmacol Physiol 1995;22(3):220-225. doi:10.1111/j. 1440-1681.1995.tb01985.x.

[23] Australian Health Ministers' Advisory Council (AHMAC). Aboriginal and Torres Strait Islander Health Performance Framework 2014 Report. [Accessed July 6, 2017]. Available from: https://www.pmc.gov. $\mathrm{au} / \mathrm{sites} /$ default/files/publications/indigenous/Health-PerformanceFramework-2014/tier-2-determinants-health/219-dietary-behaviours.html.

[24] Australian Aboriginal and Torres Strait Islander Health Survey: Updated Results, 2012-13. [Accessed July 5, 2017]. Available from: http:// www.abs.gov.au/ausstats/abs@.nsf/mf/4727.0.55.006.

[25] O'Dea K. Marked improvement in carbohydrate and lipid metabolism in diabetic Australian aborigines after temporary reversion to traditional lifestyle. Diabetes 1984;33(6):596-603. doi:10.2337/diab. 33.6.596

[26] Barker DJ, Osmond C. Infant mortality, childhood nutrition, and ischaemic heart disease in England and Wales. Lancet 1986;1(8489):10771081. doi:10.1016/S0140-6736(86)91340-1.

[27] Syddall HE, Aihie Sayer A, Dennison EM, Martin HJ, Barker DJ, Cooper C. Cohort profile: the Hertfordshire cohort study. Int J Epidemiol 2005;34(6):1234-1242. doi:10.1093/ije/dyi127.

[28] Barker DJ. Maternal nutrition, fetal nutrition, and disease in later life. Nutrition 1997;13(9):807-813. doi:10.1016/S0899-9007(97)00193-7.

[29] Roseboom TJ, Painter RC, van Abeelen AF, Veenendaal MV, de Rooij SR. Hungry in the womb: what are the consequences? Lessons from the Dutch famine. Maturitas 2011;70(2):141-145. doi:10.1016/j.maturitas.2011.06.017.

[30] de RooijSR, Painter RC, Roseboom TJ, Phillips DI, Osmond C, Barker $\mathrm{DJ}$, et al. Glucose tolerance at age 58 and the decline of glucose tolerance in comparison with age 50 in people prenatally exposed to the Dutch famine. Diabetologia 2006;49(4):637-643. doi:10.1007/ s00125-005-0136-9.

[31] Stein AD, Zybert PA, van der Pal-de Bruin K, Lumey LH. Exposure to famine during gestation, size at birth, and blood pressure at age $59 \mathrm{y}$ : evidence from the dutch famine. Eur J Epidemiol 2006;21(10):759765. doi:10.1007/s10654-006-9065-2.

[32] Roseboom TJ, van der Meulen JH, Osmond C, Barker DJ, Ravelli AC, Schroeder-Tanka JM, et al. Coronary heart disease after prenatal exposure to the Dutch famine, 1944-45. Heart 2000;84(6):595-598. doi:10.1136/heart.84.6.595.

[33] Xu Y, Wang L, He J, Bi Y, Li M, Wang T, et al. Prevalence and control of diabetes in Chinese adults. JAMA 2013;310(9):948-959. doi:10.1001/jama.2013.168118.

[34] Wang PX, Wang JJ, Lei YX, Xiao L, Luo ZC. Impact of fetal and infant exposure to the Chinese Great Famine on the risk of hypertension in adulthood. PLoS One 2012;7(11):e49720. doi:10.1371/journal. pone. 0049720

[35] Hales CN, Barker DJ. Type 2 (non-insulin-dependent) diabetes mellitus: the thrifty phenotype hypothesis. Diabetologia 1992;35(7):595601. doi:10.1007/BF00400248.

[36] Ong TP, Ozanne SE. Developmental programming of type 2 diabetes: early nutrition and epigenetic mechanisms. Curr Opin Clin Nutr Metab 
Care 2015;18(4):354-360. doi:10.1097/MC0.0000000000000177.

[37] Langley SC, Jackson AA. Increased systolic blood pressure in adult rats induced by fetal exposure to maternal low protein diets. Clin Sci (Lond) 1994;86(2):217-222; discussion 121. doi:10.1042/cs0860217.

[38] Hanson MA, Gluckman PD. Early developmental conditioning of later health and disease: physiology or pathophysiology? Physiol Rev 2014;94(4):1027-1076. doi:10.1152/physrev.00029.2013.

[39] Blackmore HL, Ozanne SE. Programming of cardiovascular disease across the life-course. J Mol Cell Cardiol 2015;83:122-130. doi:10.1016/j.yjmcc.2014.12.006.

[40] Aiken CE, Tarry-Adkins JL, Ozanne SE. Transgenerational effects of maternal diet on metabolic and reproductive ageing. Mamm Genome 2016;27(7-8):430-439. doi:10.1007/s00335-016-9631-1.

[41] Review of nutrition and growth among Indigenous peoples. [Accessed July 20, 2017]. Available from: http://www.healthinfonet.ecu. edu.au/health-risks/nutrition/plain-language/our-review.

[42] Ozanne SE. Epigenetics and metabolism in 2014: Metabolic programming - knowns, unknowns and possibilities. Nat Rev Endocrinol 2015;11(2):67-68. doi:10.1038/nrendo.2014.218.

[43] Phillips T. The role of methylation in gene expression. Nature Education 2008;1(1):116.

[44] Suzuki MM, Bird A. DNA methylation landscapes: provocative insights from epigenomics. Nat Rev Genet 2008;9(6):465-476. doi:10.1038/ nrg2341.

[45] Gabory A, Attig L, Junien C. Developmental programming and epigenetics. Am J Clin Nutr 2011;94(6 Suppl):1943S-1952S. doi:10.3945/ ajcn.110.000927.

[46] Davalos V, Esteller M. MicroRNAs and cancer epigenetics: a macrorevolution. Curr Opin Oncol 2010;22(1):35-45. doi:10.1097/CCO. Ob013e328333dcbb.

[47] Snoeck A, Remacle C, Reusens B, Hoet JJ. Effect of a low protein diet during pregnancy on the fetal rat endocrine pancreas. Biol Neonate 1990;57(2):107-118. doi:10.1159/000243170.

[48] Garofano A, Czernichow P, Bréant B. In utero undernutrition impairs rat beta-cell development. Diabetologia 1997;40(10):1231-1234. doi:10.1007/s001250050812.

[49] Zambrano E, Bautista CJ, Deás M, Martínez-Samayoa PM, GonzálezZamorano $\mathrm{M}$, Ledesma $\mathrm{H}$, Morales J, et al. A low maternal protein diet during pregnancy and lactation has sex- and window of exposure-specific effects on offspring growth and food intake, glucose metabolism and serum leptin in the rat. J Physiol 2006;571(Pt
1):221-230. doi:10.1113/jphysiol.2005.100313.

[50] Petry CJ, Dorling MW, Pawlak DB, Ozanne SE, Hales CN. Diabetes in old male offspring of rat dams fed a reduced protein diet. Int J Exp Diabetes Res 2001;2(2):139-143. doi:10.1155/EDR.2001.139.

[51] Ravelli AC, van der Meulen JH, Michels RP, Osmond C, Barker DJ, Hales $\mathrm{CN}$, et al. Glucose tolerance in adults after prenatal exposure to famine. Lancet 1998;351(9097):173-177. doi:10.1016/S01406736(97)07244-9.

[52] Portha B, Kergoat M, Blondel O, Bailbe D. Underfeeding of rat mothers during the first two trimesters of gestation does not alter insulin action and insulin secretion in the progeny. Eur J Endocrinol 1995;133(4):475-482. doi:10.1530/eje.0.1330475.

[53] Kumar PU, Ramalaxmi BA, Venkiah K, Sesikeran B. Effect of maternal undernutrition on human foetal pancreas morphology in second trimester of pregnancy. Indian J Med Res 2013;137(2):302-307.

[54] Joles JA, Sculley DV, Langley-Evans SC. Proteinuria in aging rats due to low-protein diet during mid-gestation. J Dev Orig Health Dis 2010;1(1):75-83. doi:10.1017/S2040174409990183.

[55] DeFronzo RA, Ferrannini E. Regulation of hepatic glucose metabolism in humans. Diabetes Metab Rev 1987;3(2):415-459.

[56] Hales CN, Barker DJ, Clark PM, Cox L, Fall C, Osmond C. Fetal and infant growth and impaired glucose tolerance at age 64. BMJ 1991;303(6809):1019-1022.

[57] Ozanne SE, Jensen CB, Tingey KJ, Storgaard H, Madsbad S, Vaag AA. Low birthweight is associated with specific changes in muscle insulin-signalling protein expression. Diabetologia 2005;48(3):547-552. doi:10.1007/s00125-005-1669-7.

[58] Fernandez-Twinn DS, Wayman A, Ekizoglou S, Martin MS, Hales $\mathrm{CN}$, Ozanne SE. Maternal protein restriction leads to hyperinsulinemia and reduced insulin-signaling protein expression in 21-moold female rat offspring. Am J Physiol Regul Integr Comp Physio 2005;288(2):R368-R373. doi:10.1152/ajpregu.00206.2004.

[59] McNamara BJ, Gubhaju L, Chamberlain C, Stanley F, Eades SJ. Early life influences on cardio-metabolic disease risk in aboriginal populations-what is the evidence? A systematic review of longitudinal and case-control studies. Int J Epidemiol 2012;41(6):1661-1682. doi:10.1093/ije/dys190.

[60] Williams DR, Moffitt PS, Fisher JS, Bashir HV. Diabetes and glucose tolerance in New South Wales coastal Aborigines: possible effects of non-Aboriginal genetic admixture. Diabetologia 1987;30(2):72-77. doi:10.1007/BF00274574. 